\title{
La construcción
}

del campo

criminológico

en la Institución

carcelaria* $^{*}$

/ The criminological

field construction

in prison

Institution

* Recibido: 23 de abril de 2012. Aceptado: 25 de mayo de 2012.

Tla-Melaua, Revista de Ciencias Sociales. Facultad de Derecho y Ciencias Sociales. Benemérita Universidad Autónoma de Puebla, México / IssN: 1870-6916 / Nueva Época, Año 6 № 33, Octubre 2012 - Marzo 2013, Pp. 46-65. 
RES UMEN

El trabajo parte del discurso de los sujetos implicados en el ámbito de las instituciones de encierro para comprender la práctica que desarrollan los actores sociales, particularmente los relacionados con los Consejos técnicos interdisciplinarios. Analiza el devenir histórico que siguió un cierto discurso criminológico para imponerse como teoría dominante al interior de la práctica carcelaria y, a partir de dicho proceso, estudia los diferentes momentos que lo componen: la posición de los intelectuales, la estructura de las relaciones objetivas en donde se verifican sus luchas, y las prácticas establecidas en los centros de reclusión.

PALABRAS CLAVE

Consejo Técnico Interdisciplinario, Criminología, Discurso científico, Sistemas penitenciarios.
A B S TRACT

This article initiates from a discussion of the persons involved in the area of institutionalized confinement in order to understand the practice developed by the social actors involved, particularly those related to the Interdisciplinary Technical Boards. This Analysis of the historical developments followed a criminological study that prevails as a dominant theory behind the prison practice and from this process; it also studies the different moments that are composed of: the position of intellectuals, the structure of objective relations where these struggles are verified and established practices in prisons.

KEYWORDS

Interdisciplinary Technical Boards. Criminology. Scientific discourse. Penitentiary Systems.

\footnotetext{
** Profesor del Posgrado en Derecho de la Facultad de Estudios Superiores Acatlán de la UNAM, México. (dantelopez44@hotmail.com)
} 
1. Introducción

2. Metodología

3. Marco conceptual

4. Las estrategias científicas de imposición del discurso científico

5. La posición de los intelectuales

6. Estructura de las relaciones objetivas

7. Prácticas establecidas: saber hacer las cosas

8. Resultados

9. Conclusión

\section{INTRODUCCIÓN}

La categoría de lo simbólico en la actualidad, ha condensado un gran flujo de ideas que, en ocasiones, hace imposible comprender qué se quiere decir o bien qué se nos da a entender con el empleo del término. Es por ello que, al construir nuestro objeto, nos vemos precisados a explicar lo que debería permanecer en forma implícita: para la tradición idealista, tanto la kantiana como la neokantiana, los sistemas simbólicos son instrumentos de conocimiento y de construcción del mundo objetivo, no así para la tradición estructuralista, que pretende aprehender la lógica de las formas simbólicas, su estructura inmanente, a diferencia de la tradición marxista que privilegia las funciones políticas de los sistemas simbólicos. Estas posturas permiten comprender lo simbólico en una triple dimensión: como estructuras estructurantes, como estructuras estructuradas y como instrumentos de dominación. ${ }^{1}$ Las estructuras objetivas tienden a producir prácticas que le son ajustadas. Entre las estructuras y las prácticas se ubican los agentes y sus acciones, que dan cuenta de esta relación. ${ }^{2}$

La percepción de los agentes sociales, individualmente considerados, acerca de las instituciones dependerá de su posición en el espacio social: una secretaria, un funcionario de alto o mediano nivel o un custodio tienen puntos de vista diferentes respecto del lugar en que laboran, puntos de vista que pueden ser antagónicos. Sin embargo, su práctica se ajusta al campo laboral a través de una representación que les es común, el mundo del sentido común, lo que les es evidente, simplemente hacen lo que tienen que hacer. Estas representaciones del personal que labora en las instituciones de encierro guardan relación con la representación de sentido común que las masas tienen de la cárcel: albergan a los anormales. ${ }^{3}$

\footnotetext{
${ }^{1}$ Bourdieu, Pierre, El sentido práctico, México, Siglo XXI Editores, 2010.

${ }^{2}$ Bourdieu, Pierre, Cosas dichas, trad. Margarita Mizraji, Barcelona, Gedisa, 1993, p. 55.

${ }^{3}$ Foucault, Michel, Los anormales, trad. Horacio Pons, Buenos Aires, FCE, 2000.
} 
Se decía que don Chucho dormía muy cerca de un loco que se llamaba Goyo Cárdenas y estaba allí por haber asesinado y enterrado en su patio a varias muchachas de alrededor de veinte años; lo sorprendente no era esto pues asesinos desalmados abundaban y me imagino que abundan en todas las cárceles; la gente se maravillaba porque este loco en su juventud había sido estudiante de ingeniería química del Poli con beca de Pemex y, una vez adentro de Lecumberri estudió derecho y se recibió de abogado dizque para defenderse y defender a sus compañeros sin recursos. Así que de asesino pasó a héroe popular por un simple detalle: estaba tan loco que pensaba exculparse estudiando. Si como no. ${ }^{4}$

Estas representaciones de sentido común constituyen el programa de percepción social incorporado en las mentes de los agentes, que legitima la exclusión con base en la división sano/enfermo que el devenir histórico de la institución carcelaria impuso y terminó por consagrar el Derecho; éste confiere a la vez a esa realidad su permanencia. ${ }^{5}$ La institucionalización de esta percepción social se incorporó a los centros de reclusión a través de la multidisciplinariedad: el ritual del Consejo Técnico Interdisciplinario, la práctica que los centros de reclusión verifican periódicamente.

\section{METODOLOGÍA}

Lo que asombra a quien visita por primera vez un centro de reclusión no es lo que lo distingue de la sociedad, sino su semejanza. Diferenciar lo carcelario de lo social, superar su similitud con la sociedad, constituye la base del conocimiento que pretende separar el sujeto y el objeto de conocimiento. Por el contrario, a través de este trabajo se busca reintroducir el sujeto, por lo que parte de la subjetividad, tanto del investigador como del sujeto de estudio. Es precisamente la opacidad del objeto de estudio, la cárcel, lo que nos lleva a preguntar qué es lo que hace este sistema, cuestión, desde luego, no poco problemática, particularmente si se trata de una institución capaz de producir diversas representaciones de sí misma. No obstante, asumir la institución carcelaria como fenómeno social permite su conocimiento a través del discurso, más que de los hechos. Es, pues, a través del discurso de los sujetos implicados que podemos llegar a conocer lo que esa institución lleva a la práctica y produce en el conocimiento criminológico y, en general, el campo científico implicado en el tema. ${ }^{6}$

\footnotetext{
${ }^{4}$ Sahagún Tinoco, Otilia, Mi amigo el pollo, en ... a hacer memoria, México, Archivo General de la Nación, 2000 , p. 42.

${ }^{5}$ Bourdieu, Pierre, El sentido práctico, op. cit.

${ }^{6}$ López Medrano, Dante, "Acerca del método en el sistema jurídico penal”, Revista SCLC/Estudios fu-
} 
El discurso de las personas implicadas en el objeto de estudio permite una vuelta reflexiva sobre los sujetos. Si bien el discurso generado por los actores sociales involucrados en el renglón de lo carcelario es la parte considerada, por algunas posiciones teóricas, como no científica, lo rescatamos como base de la reflexión, como elemento constituyente de lo carcelario, incluso como desorden con el que tienen que convivir las teorías que conciben lo carcelario como un orden que de vez en cuando se ve alterado, precisamente por el caos que describen dichos discursos.

Entrevistador.- Cuando vine me di cuenta de que estabas segregado, por eso ya no pude entrevistarte, ¿me podrías comentar por qué te segregaron?

Respuesta.- Por querer abrir un candado de aquí en donde hay una parte para tomar el sol, es que ya había estado mucho tiempo adentro y nos tienen con poco espacio, nos dejan salir al patio a tomar el sol o a lavar la ropa, pero yo ese día pedí permiso de salir...

E.- ¿Ibas a tomar el sol?

R.- Nomás iba a tomar el sol, pero se me negó el permiso y me sentí mal, luego les volví a decir y pues me ignoraron, y al hacer ellos eso me tomé la libertad de abrir esa puerta, pero en ese momento llegó el custodio y me dijo que no estuviera haciendo eso, quitando el candado, pero ya lo había quitado...

Le estaba metiendo un pasador, yo la verdad no sabía de eso pero ya llevaba 5 minutos ahí, y lo pude abrir, me lo quitó, como en ese tiempo andaba con mis muletas me aventó y me dijo que me fuera a la chingada, y yo lo mandé a la chingada también ¿no? Yo estaba enfermo, me mentó la madre y pues yo también, y se fue enojado, me metí pa' dentro en mi celda, después regresó con varios custodios, yo estaba en el 20, me llevaron al servicio médico para ver si estaba drogado y resultó con que no, y me llevaron a apartarme por indisciplina, al otro día fui a Consejo Técnico y me pusieron 15 días de segregación.

E.- ¿Y la gente del consejo dijo algo?

R.- No, jamás opinaron porque ellos primero me metieron y después vieron cómo habían sido los hechos, yo les pedí, les rogué que por favor no me apandaran, ¿no? Que estaba esperando mi apelación, que estudiaba, aparte, y que me portaba bien, que me dieran una oportunidad, ellos bien sabían que esa puerta debería estar abierta, pero se negaron, -me pidieron que saliera de la sala del Consejohicieron su reunión, cuando entré me dijeron que me daban 15 días.

rídicos y Políticos, México, Universidad Autónoma de Chiapas, Número 6, enero-junio 2009, pp. 11-34. 


\section{MARCO CONCEPTUAL}

¿Cómo construyó el mundo social la práctica moderna del encierro? Desde luego, el proceso histórico que instaura el discurso científico, a los técnicos, al Consejo Técnico, en la institución carcelaria de nuestro país tiene que ver con Lecumberri, la penitenciaría del Distrito Federal inaugurada el 29 de septiembre de 1901, con las diferentes prácticas que se verificaban en su interior, y su sustitución por la actual Penitenciaría de Santa Martha. Pero también con un proceso de imposición de modelos científicos desde diferentes posiciones teóricas. Lecumberri se construyó, como espacio social, como producto de la etapa de moralización que se verificó en el siglo XIX. ${ }^{7}$ Tal es su proyecto según el texto legal, los programas, las declaraciones de intención.

...aquí se elaborará la corrección del delincuente corregible, y encontrará segregación y sufrimiento, sin infamia ni horror, el incorregible; ella será siempre y para todos fórmula de la suprema ley moral de que el ataque artero o violento al derecho produce, como consecuencia necesaria, el mal que comienza en las suaves sanciones del orden civil y llega hasta la privación de la libertad y aun de la vida, en las ásperas cimas de la criminalidad. ${ }^{8}$

El programa de moralización de la institución no requería de los científicos ni de los técnicos, su necesidad no se ha planteado aún en la práctica penitenciaria que inauguró Lecumberri. El programa se encamina a la corrección moral, a través de una torre de combate contra el mal: "Aquí todo va a ser silencio, quietud, casi muerte; al poblarse estos recintos se advertirá apenas que albergan seres vivientes; al perderse el eco de vuestros pasos, comenzará el reinado del silencio y de la soledad". ${ }^{9}$

Desde luego, este fue un proyecto, el modelo que se impuso. Entre 1876 y 1880, el entonces secretario de Justicia, Ignacio Ramírez, dictó diversos acuerdos para materializar el establecimiento de la Penitenciaría de México. Así se presentaron, entre otros, el modelo de la fortaleza de Perote; los planos de los arquitectos Rivas y Plowers, y el de Medina y Ormaechea, saliendo triunfante el proyecto de Torres Torija que incorporaba el sistema celular y el

\footnotetext{
${ }_{7}^{7}$ Foucault, Michel, Microfísica del poder, trad. Julia Varela y Fernando Álvarez-Uría, $3^{\text {a }}$ edición, Madrid, La Piqueta, 1992, p. 90 y sigs.

${ }^{8}$ Macedo, Miguel S., Discurso Pronunciado en la ceremonia inaugural de la Penitenciaría de México, Álbum conmemorativo de la inauguración de la Penitenciaría de México, México, Archivo General de la Nación, 1900, pp. 8-10.

${ }_{9}^{9}$ Ídem.
} 
panóptico. ${ }^{10}$ El programa teórico fue concluido el 30 de diciembre de $1882 .{ }^{11}$ Éste, después de analizar los diferentes sistemas penitenciarios existentes en la época, se determina por el sistema Crofton o irlandés, agregándose al que ya se encontraba previsto en el texto del Código Penal de Martínez de Castro, el sistema Filadelfia: así se establece en los artículos 130 al $136 .{ }^{12}$

El sistema Filadelfia había sido recomendado por el Congreso Internacional de Francfort Sur-le-Mein, en 1846. Sin embargo, al abrigo de ulteriores congresos terminó por imponerse el sistema Crofton. Tal fue la situación de los congresos de Cincinnati de 1870 y de Londres de 1872, donde "fue unánime la preferencia en favor de los procedimientos del sistema Crofton, tal como se practica en Irlanda". ${ }^{13}$ Este sistema, a decir de sus impulsores en México, gobierna "a los hombres como dóciles ovejas". ${ }^{14}$

Para implementar este sistema tampoco hacían falta los científicos o técnicos, aunque ya se vislumbra su pálida silueta. Si bien, por una parte, de acuerdo con el proyecto de Penitenciaría de 1882, la piedra angular del sistema, premios y castigos, se encargaba a los profesores de la escuela, jefes de talleres, celadores y, desde luego, al director. ${ }^{15}$ Por otra parte, el discurso científico va perfilando su necesidad, tanto en declaraciones de propósitos como en el texto legal.

Al sistema penitenciario, reconocido como mejor por la mayor parte de los sabios en todos los congresos internacionales; al sistema nacido en Irlanda y ensayado con éxito por el capitán Crofton, que con las convenientes modificaciones aconsejadas por la experiencia y el medio, y teniendo en consideración la raza, los elementos locales, es de esperar que produzca el resultado apetecido; esto es, hacer que dentro del principio de la unidad de la pena se pueda seguir en una buena parte el de su individualización o aplicación a cada uno, del tratamiento que su modo de ser psíquico y moral exija, o sustituirlo al menos por el de clasificación según los diversos tipos aceptados. ${ }^{16}$

\footnotetext{
${ }^{10}$ González Bustamante, Juan José, La Reforma Penitenciaria en México, México, Ateneo de Ciencias y Artes de México, Cuaderno 11, 1946, p. 10 y sigs.

${ }^{11}$ Proyecto de Penitenciaría del Distrito Federal, México, Archivo General de la Nación, Fondo Gobernación, Cárceles y Penitenciarías, 1882.

${ }^{12}$ Código Penal para el Distrito y Territorio de la Baja-California sobre delitos del fuero común, y para toda la República sobre delitos contra la Federación, publicado a partir del 14 de diciembre de 1871 en el Diario Oficial del Gobierno Supremo de la República.

${ }^{13}$ Proyecto de Penitenciaría del Distrito Federal, op. cit.

${ }^{14}$ Ídem.

${ }^{15}$ Ídem.

${ }^{16}$ Alocución pronunciada en la ceremonia inaugural por el señor gobernador del Distrito Federal Lic. D. Rafael Rebollar al hacer entrega de la Penitenciaría de México al Ejecutivo de la Unión. Álbum conmemorativo de la inauguración de la Penitenciaría de México, México, Archivo General de la Nación, Fondo Gobernación, 1900, pp. 11-14.
} 
En el Reglamento de la penitenciaría, expedido con carácter de provisional en 1900, se plasma esta necesidad como parte de los servicios médicos (artículo 160). ${ }^{17}$ La materialización de este proyecto va a ser la historia de la imposición de un criterio de teoría-práctica carcelaria que se verificó en nuestro país a lo largo del siglo pasado y va a concluir con el Reglamento del Centro Penitenciario del Estado de México de 1969. En la práctica, el proyecto que inauguró Lecumberri siguió el programa de la propia institución carcelaria: su reforma. Así, a partir de 1908 la construcción original de Lecumberri empezó a sufrir modificaciones, una ampliación, por lo que se terminó con el panóptico.

Estas ampliaciones y adaptaciones consistieron en la construcción de una crujía o departamento de mujeres, cuya mayor parte hoy corresponde a la crujía "L"; los edificios para servicios médicos, gimnasio, cine, alojamiento para celadores, que ahora han sido destinados para la crujía "I" y las circulares 1 y 2 originalmente construidas para baños, en las que eran alojados los reos peligrosos o los que sufrían castigos disciplinarios, por faltas cometidas en el interior de la cárcel. ${ }^{18}$

El régimen de la disciplina y el silencio, bosquejado por Macedo en su discurso inaugural, hacia 1911 se caracterizaba por la indisciplina de los reos y la desobediencia a los superiores. La causa principal consistía en que los reos consideraban que la Revolución Mexicana debía extenderse a las cárceles, atenuando las penas y su aplicación. ${ }^{19}$

$\mathrm{Al}$ cumplir una década de su apertura el proyecto Lecumberri se encontraba agotado. Había nacido agotado, por una parte, el sistema Crofton, recomendado en los congresos de Cincinnati y Londres por ser el mejor. Para lograr la enmienda moral del reo debía implementarse tal y como se practicaba en Irlanda, lo que era imposible en Lecumberri, ya que el proyecto Irlandés no sólo incluía más de un edificio, sino que éstos se encontraban en distintas ciudades y, por otra parte, ya desde los discursos inaugurales y en el propio reglamento se aprecia la pálida silueta del modelo que se estaba imponiendo, el positivismo lombrosiano: la antropología criminal.

No obstante, el régimen planeado para regir la existencia de Lecumberri sí se llegó a materializar: "Finalmente el 26 de agosto de 1976, el 'Palacio

\footnotetext{
${ }^{17}$ Reglamentos generales de los Establecimientos penales del Distrito Federal y de la Penitenciaría de México, México, Archivo General de la Nación, Fondo Gobernación, Sección 1ª, Cárceles y Penitenciarías, 1900.

${ }^{18}$ Martín del Campo, Carlos, Antecedentes de sistemas penitenciarios de México y labor desarrollada en la Cárcel Preventiva del D.F., dentro del régimen actual, México, UAH, 1963, p. 18.

${ }^{19}$ Informe del delegado del Consejo de Dirección de la Penitenciaría de México sobre la situación que priva en ese establecimiento, diciembre 26 de 1911, México, Archivo General de la Nación, Fondo Gobernación, Sección 3ª Cárceles y Penitenciaría, 1911-1912.
} 
Negro de Lecumberri' había quedado totalmente solo, el silencio era realmente escalofriante y albergaba un eco sollozante, ahí mi abuelo y miles de presos dejaron casi toda su vida". ${ }^{20}$ La historia de Lecumberri es la historia de los accidentes y luchas que se verifican para justificar la imposición de cierta tehorein, ${ }^{21}$ mirada, la mirada científica, la mirada positiva, la transformación del reo de enfermo moral, sujeto de arrepentimiento, a otra clase de enfermo, emocional, psíquico: sujeto de reinserción.

\section{LAS ESTRATEGIAS CIENTÍFICAS DE IMPOSICIÓN DEL DISCURSO CIENTÍFICO}

Con la inauguración de Lecumberri se inicia el proceso de imposición de un nuevo discurso, portador de otra representación del mundo social, de una nueva representación del delincuente, vinculada a los intereses de los nuevos grupos.

No, Quiroz Cuarón no repetía en su clase el texto de un libro. Muchos libros y muchos hechos eran su fuente. Pero señalaba la bibliografia, tan copiosa como la quisiera y pudiera el alumno. Conocimos la Criminología, dictada por el emigrado Bernaldo de Quirós, que reunió en páginas rebosantes su erudición asombrosa. También el Compendio de LaignelLavastine y Stanciu, traducido del francés por Quiroz Cuarón.

Mejor que libros, decía, clínica criminológica; o en todo caso, no sólo libros. Fuimos a las prisiones, haciendo estudios sobre la cárcel y los presos; observamos las prácticas en el laboratorio de criminalística; asistimos a hospitales de traumatología, para asomarnos, reticentes, a la medicina forense.

Estuvimos buenas jornadas, creyéndonos ya penalistas, en la sala de visita de defensores, en Santa Marta, que era la nueva penitenciaría para varones; en la Cárcel de Mujeres; en el anfiteatro del Hospital Juárez. En Lecumberri, no. Es una cloaca, decía Quiroz. ${ }^{22}$

Lecumberri fue el espacio central en que se verificó la lucha por el monopolio de la autoridad científica, de la capacidad de decir y hacer que socialmente se reconoce a un agente determinado. ${ }^{23}$ Lucha en que concurrieron los detentadores de esa capacidad ganada en luchas precedentes y los nuevos actores, quienes van a abanderar el positivismo lombrosiano. Se identifican al menos dos grupos: los militares y los técnicos. Recuérdese que el proyecto

\footnotetext{
${ }^{20}$ Zamudio Pérez, Elizabeth, El Palacio Negro de Lecumberri, en ... a hacer memoria, op. cit., p. 12.

${ }^{21}$ Bourdieu, Pierre, Cosas dichas, op. cit., p. 132.

${ }^{22}$ García Ramírez, Sergio, Manual de Prisiones (La pena y la prisión), 4ª edición, México, Porrúa, 1998, p. 743.

${ }^{23}$ Bourdieu, Pierre, El sentido práctico, op. cit.
} 
Irlandés fue materializado por un militar, el capitán Crofton, privilegiando, desde luego, la disciplina como índice del progreso del reo, y que en este sistema, tal y como se ponía en práctica en Lecumberri, no eran necesarios los técnicos.

Lo que verdaderamente caracteriza este sistema, es la división de la pena en cuatro periodos, clasificados según la mayor severidad y basados en el doble principio de ofrecer premio a la buena conducta y a la enmienda, y de amenazar con castigo la perseverancia en el delito o en la inmoralidad... El primer periodo es de prisión celular... El objeto de este rigor es hacer al reo entrar en sí mismo y producir en su espíritu una impresión profunda... El segundo grado es de prisión en común, con separación durante la noche y trabajo en la escuela y en el taller durante el día... La base de este grado es una clasificación progresiva fundada en la buena conducta... La distribución de premios se hace por el jefe de los talleres, el profesor de la escuela, los guardianes o celadores principales y el gobernador de la prisión... El tercer periodo, que es propiamente el último de la pena, tiene por objeto hacer ver al reo que ya se tiene confianza en él, a consecuencia de los progresos que ha hecho, y probar al público que su conducta ofrece garantías que permiten emplearlo y tratarlo con seguridad, sirviendo al propio tiempo para comprobar la realidad de la reforma de los criminales y su poder sobre sí mismo para resistir a las tentaciones y ver cómo preparan su vuelta a la sociedad... ${ }^{24}$

Esta lucha se identifica por las estrategias de descalificación del adversario, tomando como objeto de conocimiento a los propios contrincantes y sus estrategias. ${ }^{25}$ Se materializa en la sucesión de técnicos y militares en la dirección del propio penal, y culmina con el final de Lecumberri, la apertura del Centro Penitenciario del Estado de México, la Penitenciaría de Santa Martha y los reclusorios preventivos en el Distrito Federal. Se simboliza en el acto del nombramiento del último director: el cambio de director se verificó cuatro meses antes del final de Lecumberri.

En la noche de ese 30 de abril -de 1976- fuimos a Lecumberri el Regente de la ciudad, el Procurador del Distrito, el Director de la Policía, General Gutiérrez Santos, funcionario esmerado y capaz, el Director General de Gobernación, de quien la cárcel dependía,

\footnotetext{
${ }^{24}$ Proyecto de Penitenciaría del Distrito Federal, op. cit.

${ }^{25}$ Bourdieu, Pierre, El sentido práctico, op. cit.
} 
licenciado Jorge Espínola Samperio, el Secretario General de Gobierno del Distrito, el respetable jurista doctor Octavio Hernández, y el doctor Gustavo Malo Camacho, Presidente de la Comisión Administradora de los Reclusorios.

En el despacho de la Dirección hubo una breve ceremonia: fue generosa la presentación que de mí hizo el Jefe del Departamento del Distrito Federal y yo di a conocer mi reconocimiento al Presidente de la República, Luis Echeverría, y a las autoridades de la ciudad, y mi formal compromiso al frente de Lecumberri.

Momentos después acompañé en su salida al exdirector, general Francisco Arcaute Franco, en el primer acto de mi cargo, visité una a una las crujías de Lecumberri. Cerca de la media noche la cárcel estaba en silencio. ${ }^{26}$

En este proceso se identifican tres momentos que contienen igual número de niveles de realidad social: la posición de los intelectuales, la estructura de las relaciones objetivas en donde se verifican estas luchas y las prácticas establecidas. $^{27}$

\section{LA POSICIÓN DE LOS INTELECTUALES}

La posición de los intelectuales, quienes en algún momento ocuparon cargos de dirección en Lecumberri, se centró en dos sentidos: la descalificación de la práctica y proyecto que se verificaba en Lecumberri, que se resume en: nada funciona nada puede funcionar; y plantear la necesidad de la reforma penitenciaria. Estas estrategias se desarrollaron a través de la Academia Mexicana de Ciencias Penales y su órgano de difusión, la revista Criminalia, el campo académico y los congresos nacionales penitenciarios. Lugares en los que no tuvieron espacio los defensores de otros proyectos: los militares. Es suficiente revisar quienes participaban en esos tres espacios para constatarlo.

El primer Congreso Nacional Penitenciario se llevó a cabo del 24 de noviembre al 3 de diciembre de 1932, en Aguascalientes. El aludido evento fue presidido por José Ángel Ceniceros, y abordó, entre otros temas, el siguiente: "Medios de tratamiento de los reos dentro de las prisiones y condiciones que deben llenar para lograr la readaptación de los delincuentes". ${ }^{28}$ En 1936 Raúl Carrancá y Trujillo escribió: "Los delincuentes mismos participan principalmente en la organización interior del penal al mismo tiempo que se carece en lo absoluto de Oficiales de Prisiones, personal técnicamente

\footnotetext{
${ }^{26}$ García Ramírez, Sergio, El final de Lecumberri (Reflexiones sobre la prisión), México, Porrúa, 1979, pp. 21 y sigs.

${ }^{27}$ Bourdieu, Pierre, El sentido práctico, op. cit.

${ }^{28}$ García Ramírez, Sergio, Manual de Prisiones, op. cit., p. 437 y sig.
} 
especializado, pues el que figura en las nóminas se improvisa y no acredita estudios previos de ningún género". ${ }^{29}$

En un informe elaborado en 1936 por Ignacio García Téllez, entonces procurador General de Justicia de la Nación, dirigido al presidente Lázaro Cárdenas, recomendó: "Que se proceda, desde luego, a reorganizar nuestro régimen penitenciario, con sinceros propósitos de regeneración del delincuente..." ${ }^{30}$ Producto de las observaciones y recomendaciones del procurador García Téllez, se elaboró el Reglamento de la Penitenciaría, que en su artículo 10 dispuso la creación de un Departamento de Prevención Social, compuesto por un jefe médico psiquiatra especialista en Criminología, una Unidad de médicos psiquiatras "encargados de realizar los estudios médicos psicológicos de los delincuentes para la clasificación, distribución y tratamiento de estos...", así como de "los trabajadores sociales cuya labor consistirá en las investigaciones de índole social complementarias de los estudios médicos psicológicos, tendientes al conocimiento integral de los delincuentes". ${ }^{31}$ Para materializar la reforma penitenciaria se designó, en febrero de 1936, como director de Lecumberri a Carlos Franco Sodi, quien resumió su labor de dieciocho meses, señalando: _fracasép ${ }^{32}$

Una década después, hacia 1946, Juan José González Bustamante criticó el hecho de que en la práctica carcelaria de Lecumberri no se siga ningún método científico. Asimismo, que el Departamento de Prevención Social no tenga participación en la vida carcelaria y tratamiento de los internos, y que ésta se rija por el arbitrio del director. ${ }^{33}$

Cada establecimiento de corrección penal debe contar con un Departamento de Observación de los reclusos, para estudiar sus antecedentes, su género de vida, sus taras hereditarias, sus tendencias criminales, etc., etc., como fase inicial del tratamiento que debe aplicárseles. Este departamento debe estar integrado por personas expertas en Criminología, Psiquiatría y Pedagogía: verdaderos auxiliares técnicos para que la Justicia Penal cumpla eficazmente con su cometido. ${ }^{34}$

Se pretende el desplazamiento de la mirada, de una observación con el fin de que el interno se sienta vigilado para que enmiende su comportamiento, conforme a los principios del panóptico, a una observación con la finalidad de detectar tendencias criminales. En los primero días de enero de 1947, Franco Sodi invitó a Javier Piña y Palacios a ocupar el cargo de direc-

\footnotetext{
${ }^{29}$ Carrancá y Trujillo, Raúl, "La reforma penitenciaria en México”, Criminalia, México, año III, núms. 1 al 12, septiembre 1936-agosto 1937.

${ }^{30}$ García Téllez, Ignacio, "La reforma penitenciaria", Criminalia, México, año IV, núm. 3, 1 de noviembre de 1937.

${ }^{31}$ Ídem.

${ }^{32}$ Franco Sodi, Carlos, Don Fuan delincuente y otros ensayos, México, Botas, 1951.

${ }^{33}$ González Bustamante, Juan José, op. cit., p. 10 y sigs.

${ }^{34}$ Ídem.
} 
tor de la Penitenciaría del Distrito Federal, quien se impuso como principal ocupación dar cumplimiento al artículo 18 de la Constitución Política de los Estados Unidos Mexicanos:

Se formuló un proyecto que consistía en aislar una de las más grandes crujías, del resto de la prisión. Adicionarle un pabellón que se destinaría a la selección, estudio y clasificación de los sentenciados, para poder distribuirlos en las diferentes secciones en las que debería dividirse la crujía, para la clasificación y el tratamiento necesarios. ${ }^{35}$

Durante su encargo como director de la Penitenciaría, Piña y Palacios viajó a los Estados Unidos con el fin de conocer el trabajo penitenciario de ese país. En Washington, el director de Prisiones le enseñó el manual que un grupo de directores de prisiones acababa de publicar: "En él estaban contenidos todos los lineamientos de la organización y funcionamiento de los Consejos Técnicos Interdisciplinarios que deben manejar las prisiones". ${ }^{36}$

El segundo Congreso Nacional Penitenciario se celebró del 26 de octubre al 1 de noviembre de 1952. La convocatoria la realizaron: la Universidad Nacional Autónoma de México, el gobierno del Estado de México, la Sociedad Mexicana de Medicina Forense y Criminología, la Sociedad Mexicana de Neurología y Psiquiatría, la Academia Mexicana de Ciencias Penales y la Asociación de Funcionarios Judiciales. Entre los temas centrales del congreso encontramos: la biotipología criminal, la resocialización de los delincuentes, el servicio médico en las penitenciarías y los establecimientos penitenciarios en relación con su arquitectura, entre otros. ${ }^{37}$ En este congreso se planeó el Centro Penitenciario del Estado de México. ${ }^{38}$

El 3 de marzo de 1958, al efectuarse el primer traslado de reos al penal de Santa Martha, Lecumberri dejó de tener carácter de Penitenciaría. Aquel se inauguró el 14 de octubre de 1957, pero comenzó a funcionar a partir del primer traslado de reos. Inicialmente, Lecumberri tuvo funciones de cárcel preventiva designándose como director a un militar, el general Carlos Martín del Campo, quien asumió la dirección de la Cárcel Preventiva para hacer cumplir las Reglas Minimas aprobadas en Ginebra en 1955, con particular énfasis en el trabajo como medio de rehabilitación. ${ }^{39}$ Así, si bien hacia 1950 no habia ni médico, salvo cuando se llamaba a algún facultativo del exterior, para 1963,

\footnotetext{
${ }^{35}$ Piña y Palacios, Javier, "Lecumberri: mi casa durante dos años", Criminalia, México, año XLV, números 1-3, enero-marzo, 1979, p. 115.

${ }^{36}$ Ídem.

${ }^{37}$ García Ramírez, Sergio, Manual de Prisiones, op. cit., p. 437 y sigs.

${ }^{38}$ García Ramírez, Sergio, El final de Lecumberri (Reflexiones sobre la prisión), op. cit.

${ }^{39}$ Martín del Campo, Carlos, La rehabilitación desde procesados, México, Talleres Industriales de la Cárcel Preventiva, 1966.
} 
debido a las gestiones del general Martín del Campo, el cuerpo técnico se componía de un médico de guardia permanente, dos dentistas, dos radiólogos, un urólogo, un cirujano, dos psiquiatras, un tisiólogo, dos internistas, un anestesista, un neurólogo, un ortopedista y un oculista. Había, además, seis médicos que cubrían guardia cada día de la semana. ${ }^{40}$ Términos equivocados, personal equivocado, fines equivocados: fracaso del proyecto encabezado por militares.

\title{
6. ESTRUCTURA DE LAS RELACIONES OBJETIVAS
}

Los límites del moderno penitenciarismo se han construido para evitar el rechazo tanto del castigo como de la instancia que castiga, lo que se ha logrado al humanizar el dolor.

\begin{abstract}
Ahí enraíza el principio de que no se debe aplicar jamás sino castigos "humanos" a un delincuente que, sin embargo, puede muy bien ser un traidor y un monstruo. La razón de que la ley deba tratar ahora "humanamente" a aquel que se halla "fuera de la naturaleza" (mientras que la justicia de antaño trataba de manera inhumana al "fuera de la ley"), no está en una humanidad profunda que el delincuente escondiera dentro de sí, sino en la regulación necesaria de los efectos de poder. Esta racionalidad "económica" es la que debe proporcionar la pena y prescribir sus técnicas afinadas. "Humanidad" es el nombre respetuoso que se da a esta economía y a sus cálculos minuciosos. "En cuestión de pena, el mínimo está ordenado por la humanidad y aconsejado por la política". ${ }^{41}$
\end{abstract}

Los órganos de gobierno encargados de la protección de los Derechos Humanos, en la actualidad, hablan de esta aporía: la humanización de las penas. No obstante, existe consenso en señalar que la cárcel no cumple con los fines para los cuales está diseñada. Esto es así porque cumple con otro tipo de funciones, más bien simbólicas.

En la dinámica carcelaria, más allá del discurso oficial, la población reclusa se distribuye por sí sola en el interior de los dormitorios: los internos son canalizados directamente a través de Seguridad y Custodia, por medidas de seguridad o bien porque las estancias las han vendido al mejor postor; sea porque los propios criterios son ambiguos y se presten a las simpatías o antipatías del personal técnico encargado de realizar la clasificación o a causa de que los reclusos de más antigüedad no permitan el ingreso, en la

\footnotetext{
${ }^{40}$ Martín del Campo, Carlos, Antecedentes de sistemas penitenciarios de México, op. cit.

${ }^{41}$ Foucault, Michel, Vigilary Castigar. El nacimiento de la prisión, México, Siglo XXI Editores, 2008, p. 96.
} 
estancia, a los más recientes. Esta última dinámica produce el fenómeno de los damnificados: aquellos internos que por no tener poder político, económico y social, entre otros, no pueden hacer valer su derecho a tener un lugar en la exclusión, y se ven obligados a vivir en los pasillos, durmiendo hacinados. Más allá de estos lugares existen las zonas de los olvidados. Los lugares de castigo. La exclusión dentro de la exclusión.

Miembro del Consejo Técnico.- En alguna ocasión se sometió a consideración del Consejo Técnico Interdisciplinario de la Penitenciaría del Distrito Federal el caso de un interno que había sido trasladado del Centro Federal de Readaptación Social número 1, conocido popularmente como el Penal de Alta Seguridad de Almoloya, más tarde La Palma y Centro Federal Número 1. El caso consistía en que cuando llevaron a esa persona a la Penitenciaría fue recibido por el personal de Seguridad y Custodia, siendo ellos quienes se encargaron de canalizarlo a un dormitorio de alta seguridad, y posteriormente el interno solicitaba ser cambiado a dormitorios comunes, conocidos como población general. Se argumentaba para sustentar una opinión favorable a su solicitud, por parte del director del Penal, que el interno había prometido portarse bien, y que además se debería tomar en cuenta que si lo habían trasladado de Almoloya, era porque en aquel lugar no lo consideraban de alta peligrosidad. Ante ello el Subdirector Técnico hizo la observación de que en los estudios técnicos de esa persona, realizados en el propio penal de Almoloya, se le había diagnosticado como un interno de alta peligrosidad. El voto del Consejo fue mayoritariamente en contra de que pasara a población general. Al final, se concedió la oportunidad que el interno solicitaba dada la defensa del director.

El fracaso de la cárcel, en cuanto al cumplimiento de sus fines declarados, se constata en las recurrentes recomendaciones que sobre los centros de reclusión han emitido las comisiones de derechos humanos. Es claro que el programa de este tipo de instituciones plantea corregir el funcionamiento de la cárcel, sin que se cuestione su existencia misma o, al menos, su programa de reinserción. Este tipo de organismos conforman, en consecuencia, el más reciente de los mecanismos que acompañan a la cárcel, con la apariencia de corregirla, pero que sirven para justificarla, por lo que la posición que delinean estos organismos sobre la cárcel se puede considerar como una lectura de autoengaño. ${ }^{42}$

\footnotetext{
${ }^{42}$ Tenorio Tagle, Fernando, Ideas Contemporáneas en torno a las Drogas y sus Consecuencias en Materia Legislativa, México, INACIPE, 1992, p. 18.
} 


\section{PRÁCTICAS ESTABLECIDAS: SABER HACER LAS COSAS}

La cotidianidad carcelaria se nos presenta como un universo natural, en donde los profesionistas, de cualquier campo del conocimiento, se insertan en una práctica incuestionada, simplemente para hacer lo que saben hacer, pero, ¿qué saben hacer? y ¿cómo es que saben lo que hay que hacer?

Psicólogo.- al presentarme a laborar, por primera vez, en un reclusorio del Distrito Federal, en el área llamada de Gobierno -alberga la dirección, custodia y administración- pregunté a un custodio por el director de la institución -quien estaba sentado a un lado de donde nos encontrábamos, justo afuera de la Dirección-, él me lo señaló, y entonces, el director, que había escuchado, preguntó el motivo de mi visita. Le presenté un oficio mediante el que se me presentaba como psicólogo e indicaba que a partir de ese día trabajaría en ese lugar. El director me observó con detenimiento y me dijo que cómo era posible que fuera psicólogo y no me hubiera percatado que él era el director.

La práctica simplemente se va imponiendo al científico, quien acepta su lugar y especificidad como algo natural, evidente, incuestionable. Se inserta en un espacio social que además se encuentra delimitado por lo jurídico. Pero esto no siempre fue así, la práctica que el profesionista lleva a cabo en el espacio carcelario se ha construido, es un producto histórico y, como tal, arbitrario.

De todo aquel psicólogo que ingresa a laborar al sistema de reclusorios se espera que aplique pruebas psicométricas, las pueda interpretar o calificar, conducir una entrevista y, finalmente, emitir un reporte; para ello en la Universidad se le enseñan ciertos instrumentos metodológicos. Uno de los instrumentos empleados por el psicólogo de las prisiones es el test de la figura humana. En la aplicación se solicita al sujeto de estudio que realice el dibujo de una persona, y sobre éste se aplica la técnica de la interpretación.

Psicólogo.- en cierta ocasión al estar trabajando en la interpretación de unos dibujos realizados por un preso, acudí a pedir la opinión del jefe de la Oficina de Psicología, mismo que tomó el dibujo, lo vio brevemente, y me dijo: “... es un sujeto joven, tipo zángano, vividor... seguramente es de esas personas que se paran en las esquinas a asaltar a los que pasan."

Estas herramientas y recursos técnicos pueden emplearse como expedientes de conocimiento del objeto de estudio. Sin embargo, también "pueden emplearse en forma inconsciente ante todo como defensas aisladoras que 
desfiguran nuestra percepción de la realidad y estorban la investigación en varios modos". ${ }^{43}$ Pero, ¿qué realidad es esta que es desfigurada?

Únicamente enunciaremos algunos aspectos que nos interesa señalar. Actualmente, el trabajo del personal de reclusorios, en particular nos referimos al área técnica (funcionarios, psicólogos, trabajadores sociales, médicos, psiquiatras y criminólogos), se convierte en un trabajo avalador: al individualizar el conflicto, justifica el trabajo de otras instancias de selección de internos. Siguiendo la normatividad, una vez que el sujeto ingresa a la Institución total, ${ }^{44}$ el cuerpo médico lo observa a efecto de indicar únicamente si ingresó con lesiones, no para la atención de su salud física o mental. El psicólogo aporta solamente su presencia, ya que si los sujetos requieren apoyo emocional lo reciben de sus compañeros de reclusión, y del cuerpo de Seguridad y Custodia.

La tarea más ingrata es la del criminólogo, quien avala o justifica que el sujeto esté en el encierro y cuyos diagnósticos contienen invariablemente la etiqueta de peligroso. El interno es más o menos peligroso, pero la categoría de no-peligroso está negada, no existe, y en el peor de los casos el sujeto es extremadamente peligroso. Es notable que esta práctica, de diagnosticar a los internos como peligrosos, se realice en los reclusorios y centros penitenciarios del país, aún y cuando tal categoría fue eliminada expresamente de las leyes penales. Esto es así porque se ha incorporado al habitus, porque es una práctica que ya ni siquiera se plantea si tiene fundamento legal. En todo caso el criminólogo, con los elementos que le presentan las demás áreas técnicas, debe explicar los motivos que determinaron o impulsaron al delincuente y establecer su grado de culpabilidad, término ajeno a la práctica criminológica y que incluso el Derecho penal contemporáneo está expulsando de su andamiaje teórico, entre otras razones por su fuerte contenido moral. ${ }^{45}$

Por otra parte, el criminólogo que trabaja en prisión debe realizar de tres a cinco estudios al día, es decir, uno cada hora, por lo que las exigencias laborales lo llevan a aprender a hacer las cosas: como su estudio es síntesis, se toma demasiado en serio esta metodología.

Criminólogo.- En alguna ocasión el jefe de Oficina de Criminología de uno de los reclusorios del Distrito Federal, señalaba indignado que en ese centro una secretaria había solicitado plaza de criminólogo,

\footnotetext{
${ }^{43}$ Devereux, George, De la ansiedad al método en las ciencias del comportamiento, $13^{\text {a }}$ edición, México, Siglo XXI Editores, 2008, p. 120.

${ }^{44}$ Goffman, Erving, Internados. Ensayo sobre la situación social de los enfermos mentales, trad. María Antonia Oyuela de Grant, Buenos Aires, Amorrortu, 2007.

${ }^{45}$ López Medrano, D. Dante, "Los límites del Derecho penal subjetivo", en Rabasa Gamboa, Emilio y López Medrano, D. Dante (coords.), Problemas actuales del Derecho penal mexicano, México, Porrúa, 2010, pp. 91-128.
} 
ya que con el tiempo que tenía transcribiendo estudios ya sabía cómo se hacían: había que tomar una parte del estudio que remitía psicología, una parte del de trabajo social, de pedagogía, y eso era todo. De esta forma existen criminólogos que se ufanan de poder realizar cinco o más estudios al día.

Los conflictos relativos a la población interna, así como los legales, de relación y de satisfacción de necesidades, se resuelven en el plano donde el técnico nada tiene que ver. Mientras el técnico clasifica a la población en diferentes dormitorios, a partir de los resultados que arrojan sus estudios, en la dinámica de la vida en reclusión se realizan reclasificaciones, auspiciadas por las autoridades, los cuerpos de seguridad o los mismos internos. Poco o nada tiene que ver el técnico con la vida de los internos.

\section{RESULTADOS}

Si el científico social construye sus objetos de conocimiento, el científico que trabaja en los centros de reclusión los simula. Conocer acerca de una problemática social implica, en sí, una toma de postura. ${ }^{46}$ Toma de postura que se manifiesta desde el inicio de la investigación, y se acentúa o diluye en las diferentes etapas: en la determinación de los individuos a investigar; selección de las técnicas y el diseño de los instrumentos de recolección de datos; en la formulación de la estrategia y el desarrollo del trabajo de campo, y en el análisis de la información empírica. La toma de postura tiene que ver con la posición que se tenga en la jerarquía de poder, la posición de los grupos en el campo intelectual y el habitus. ${ }^{47}$

La metodología aplicable en el sistema privativo de libertad individualiza el conflicto, construye objetos de conocimiento distintos de los objetos reales. "Los objetos de conocimiento son representaciones, ficciones, simulacros, metáforas de los objetos reales, mientras éstos últimos, según ciertas opiniones, sólo sirven para engañar al investigador" ${ }^{48}$ ¿Son constatables estas ideas de simulación, del simulacro de la reinserción? Para dar respuesta, recurrimos al discurso de un interno a quien llamaremos El Chucky.

El relato inicia cuando El Chucky ingresa a reclusión, y es puesto a disposición del juez. El Chucky inicia su proceso de adaptación al nuevo medio, nuevo para él. Pronto se da cuenta que en reclusión impera la ley del más fuerte y la extorsión, auspiciada por los custodios. Sabe que tiene que adoptar posturas fieras, de reto, tal vez así lo dejen en paz. También descubre que

\footnotetext{
${ }^{46}$ Lourau, René, El diario de investigación. Materiales para una teoría de la implicación, trad. Emmanuel Carballo Villaseñor, Guadalajara, Universidad de Guadalajara, 1989.

47 Bourdieu, Pierre, El sentido práctico, op. cit.

${ }^{48}$ Lourau, René, op. cit., p. 37.
} 
su vida de asaltante - "yo allá afuera me dedicaba a asaltar, asalto a mano armada"- le ha proporcionado "valedores" que se encuentran en prisión y que lo van a ayudar. Entiende que el grupo hace la fuerza que le permite resistir. Así, consigue trabajo como ayudante de limpieza, como sirviente de un padrino.

De esta forma se entera que la droga y el alcohol ingresan al reclusorio con la connivencia y participación de las autoridades, ve como los propios custodios le llevan cocaína al padrino y observa como éste la consume y distribuye. Esta forma de vida le permite un ingreso económico para sus propios gastos de vestido y alimentación, y para poder darse su "toque", fumar marihuana. También presencia que algunos internos abusan sexualmente de otros... "es que aquí todos temen por sus mujeres, imagínese que un güey abuse de ella, todos tienen mamá o hermanas, o hijos, por eso no se quiere a los violadores".

En el internamiento de El Chucky, también existe el correctivo disciplinario: "Me colgué de la lista, y los custodios querían que les pagara. No, pos me negué. Y que me les pongo bien al chile. Hasta llamaron al jefe de seguridad. Me enviaron al módulo de máxima seguridad, apandado por culero. Me querían meter miedo, me dijeron que ya me habían encargado con la persona que estaba en la celda, en el apando, a donde me iban a llevar. No, pues sí, me dio miedo. Y que voy entrando, y no pues que era El Maguey. Ya lo conocía, me dijo: qué onda, porqué te trajeron... ya después salí”.

El Chucky es llamado, entonces, por primera vez por el staff experto. Le hacen preguntas acerca de su vida, del delito, de lo que hace en el reclusorio... Pero esto a él no le interesa, le interesa quedar bien y decir lo que quieren escuchar: que todo fue un error, que es inocente, que lo torturó la policía, que sufre mucho, que nunca había conocido a una persona tan humana y comprensiva como la que tiene enfrente... Sabe esto porque ya se lo dijeron los demás internos. Que así tenía que conducirse, que así tenía que ser. Después de dos o tres días de acudir con el staff experto se olvida de ellos.

Llega el día en que es trasladado a la penitenciaría, en donde el proceso se repite, sólo que ahora con la diferencia del color: viste de color azul. Con el paso de los años va perdiendo a su familia, por muerte o desintegración. Ahora quiere salir. "No, pos también me pelié con la licenciada, la de prevención, le dije que al salir iba a seguir asaltando, que nunca trabajé, y que aquí no aprendí a hacer nada útil, no pos así cómo quería que me ayudara, me dijo, que debería recapacitar, ya portarme bien, ¡chale!, yo no entiendo si uno les dice las cosas como son, se enojan y dicen que uno es cínico, qué, ¿quieren oír puras mentiras como las que todos cuentan?”

Sin embargo, El Chucky se decía a sí mismo, en ocasiones en voz alta, que cuando saliera de prisión sería lo que era antes de entrar a ella: asaltante. Sólo que ahora había aprendido que la prisión no es nada bueno: "Yo aquí 
ya no regreso... prefiero que me maten. Sí, si ya la veo perdida, antes que entregarme prefiero que me maten. ¿Qué otra cosa puedo hacer al salir? Nunca he hecho nada, no se trabajar en nada". A los pocos días de esta reflexión salió de prisión: beneficios de libertad anticipada. Una vez a punto de la reinserción, se le canalizó al Centro especializado, y a los pocos días salió en situación de preliberado. Posteriormente, me enteré, a través de una psicóloga del centro de reclusión que lo vio, que era vendedor ambulante en el Sistema de Transporte Colectivo de la Ciudad de México, el Metro.

\section{CONCLUSIÓN}

Para entender la finalidad del castigo en nuestro momento cultural, sobre el fin de la prisión, debemos intentar aprehenderla más allá del concepto de reinserción, que, como hemos visto, es una construcción cultural y, por tanto, arbitraria. Sin embargo, esta postura fatalmente nos lleva a la respuesta que Nietzsche da a la pregunta: ¿por qué se castiga en la actualidad? "En la actualidad es imposible decir de modo determinado porqué se castiga". ${ }^{49}$

La reinserción como finalidad de la prisión no es más que una imagen, pero ¿imagen de qué? De una realidad profunda o de ningún tipo de realidad. De tal manera que:

Las fases sucesivas de la imagen serían éstas:

- es el reflejo de una realidad profunda

- enmascara y desnaturaliza una realidad profunda

- enmascara la ausencia de realidad profunda

- no tiene nada que ver con ningún tipo de realidad, es ya su propio y puro simulacro.

En el primer caso, la imagen es una buena apariencia y la representación pertenece al orden del sacramento. En el segundo, es una mala apariencia y es del orden de lo maléfico. En el tercero, juega a ser una apariencia y pertenece al orden del sortilegio. En el cuarto, ya no corresponde al orden de la apariencia, sino al de la simulación. ${ }^{50}$

\footnotetext{
${ }^{49}$ Nietzsche, Friedrich, La genealogía de la moral. Un escrito polémico, trad. José Mardomingo Sierra, Madrid, Edaf, 2000, p. 128.

${ }^{50}$ Baudrillard, Jean, Cultura y simulacro, trad. Antoni Vicens y Pedro Rovira, $5^{\text {a }}$ edición, Barcelona, Kairós, 1998, p. 18.
} 